Document downloaded from:

http://hdl.handle.net/10251/45167

This paper must be cited as:

Salvador, FJ.; Martínez López, J.; Caballer Fernández, M.; Alfonso Laguna, CD. (2013). Study of the influence of the needle lift on the internal flow and cavitationphenomenon in diesel injector nozzles by CFD using RANS methods. Energy Conversion and Management. 66:246-256. doi:10.1016/j.enconman.2012.10.011.

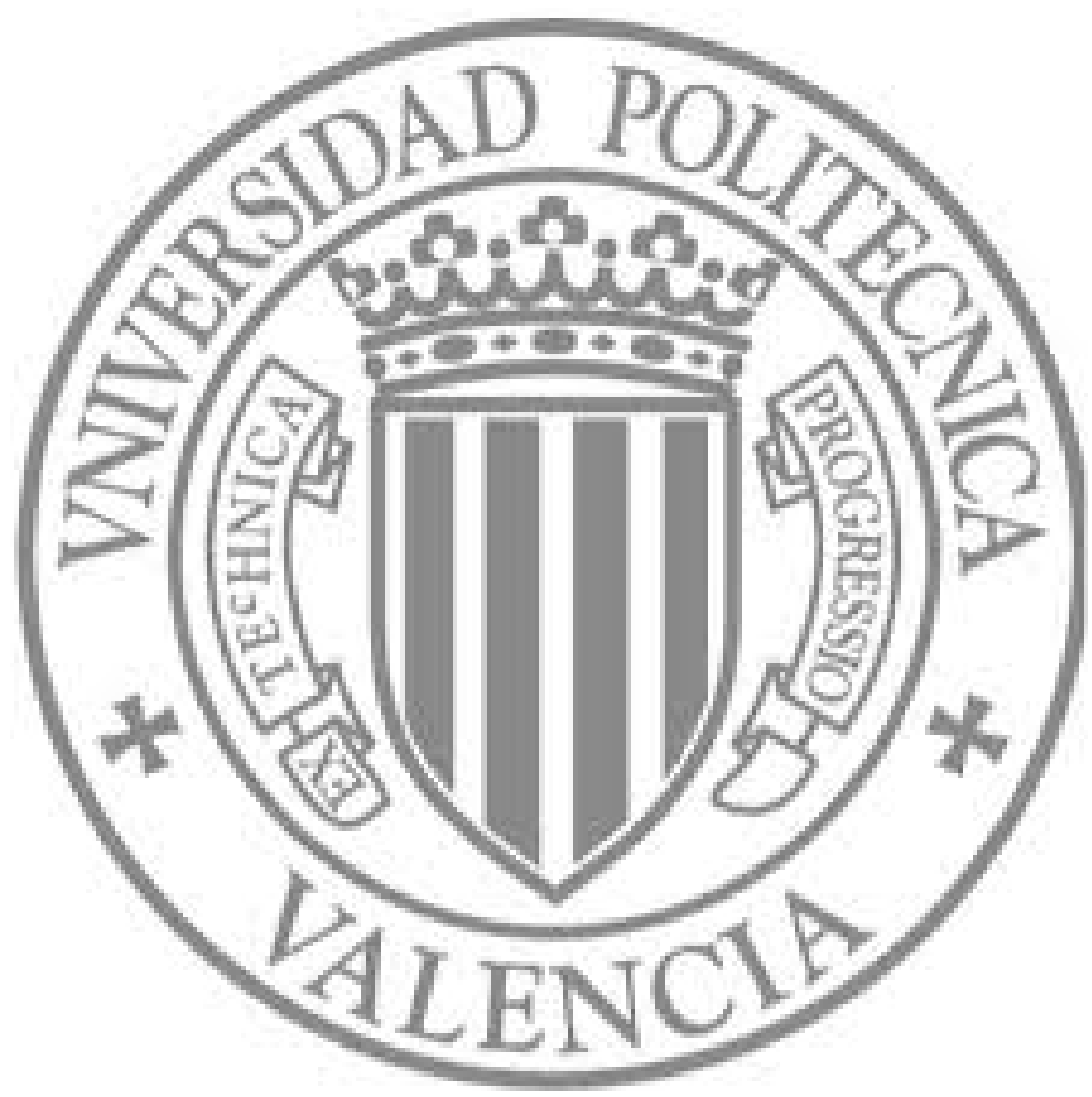

The final publication is available at

http://dx.doi.org/10.1016/j.enconman.2012.10.011

Copyright Elsevier 


\section{STUDY OF THE INFLUENCE OF THE NEEDLE LIFT ON THE INTERNAL FLOW AND CAVITATION PHENOMENON IN DIESEL INJECTOR NOZZLES BY CFD USING RANS METHODS}

Salvador, F.J. ${ }^{1}$ (*), Martínez-López, J. ${ }^{1}$, Caballer, M. ${ }^{2}$, De Alfonso, C. ${ }^{2}$

${ }^{1}$ CMT-Motores Térmicos, Universitat Politècnica de València

Camino de Vera s/n, E-46022 Spain.

${ }^{2}$ Instituto de Instrumentación para Imagen Molecular (I3M),

Centro Mixto CSIC- Universitat Politècnica de València- CIEMAT

Camino de Vera s/n, 46022 Spain.

(*) Corresponding author:

Dr. F. Javier Salvador, fsalvado@mot.upv.es

CMT-Motores Térmicos, Universitat Politècnica de València

Camino de Vera s/n, E-46022 Spain.

Telephone: +34-963879659

FAX: $+34-963877659$ 


\section{ABSTRACT}

It is well known that cavitation phenomenon in diesel injector nozzles has a strong influence on the internal flow during the injection process and spray development. However, its influence on the flow during needle opening and closing remains still unclear due to the huge difficulties related to performing experiments at partial needle lifts.

In this paper, an extended computational study has been performed in a multi-hole nozzle modeling ten different fixed needle lifts. The internal flow has been modeled with a continuum nozzle flow model that considers the cavitating flow as a homogeneous mixture of liquid and vapour. Due to high Reynolds numbers, turbulence effects have been taken into account by RANS methods using a RNG k- $\varepsilon$ model.

Firstly, the code has been validated against experimental data at full needle lift conditions in terms of mass flow, momentum flux and effective velocity, showing a fairly good agreement with experimental results.

Once the code has been validated, it has been possible to study in depth the internal nozzle flow and its characteristics at the outlet at different partial needle lifts. Nevertheless, not only the main flow features have been explained, but also the cavitation appearance and the turbulence development, which present huge differences between the different needle lifts simulated.

\section{KEYWORDS}

Cavitation, diesel, needle lift, injection, nozzle. 


\section{LIST OF NOTATION}

\section{NOMENCLATURE}

a speed of sound

A area

$A_{\text {eff }} \quad$ outlet effective area

$A_{o} \quad$ outlet area

$\mathrm{C}_{\mu} \quad$ constant for turbulent viscosity calculation

$\mathrm{C}_{\varepsilon 1} \quad$ constant for $\varepsilon$ transport equation calculation

$\mathrm{C}_{\varepsilon 2} \quad$ constant for $\varepsilon$ transport equation calculation

$C_{a} \quad$ area coefficient

$C_{d} \quad$ discharge coefficient

$C_{v} \quad$ velocity coefficient

$D_{\text {eff }} \quad$ effective diameter

$D_{i} \quad$ diameter at the orifice inlet

$D_{o} \quad$ diameter at the orifice outlet

$k \quad$ turbulent kinetic energy

$k$-factor orifice conicity factor

L orifice length

$m_{\mathrm{f}} \quad$ mass flow

$M_{\mathrm{f}} \quad$ momentum flux

$p \quad$ pressure

$P_{\text {back }} \quad$ discharge back pressure

$P_{i n j} \quad$ injection pressure

$P_{k} \quad$ production of turbulent kinetic energy

$p_{\text {sat }} \quad$ vaporisation pressure 


$\begin{array}{ll}r & \text { rounding radius at the inlet orifice } \\ t & \text { time } \\ u & \text { velocity } \\ \bar{u} & \text { velocity vector } \\ u_{\text {eff }} & \text { effective velocity } \\ u_{t h} & \text { theoretical velocity }\end{array}$

\section{GREEK SYMBOLS:}

$\gamma \quad$ vapour mass fraction

$\varepsilon \quad$ turbulence dissipation rate

$\Delta P \quad$ pressure drop, $\Delta P=P_{i n j}-P_{b a c k}$

$\mu \quad$ fluid viscosity

$\mu_{l} \quad$ liquid viscosity

$\mu_{T} \quad$ turbulent viscosity

$\mu_{v} \quad$ vapour viscosity

$\sigma_{\varepsilon} \quad$ constant for $\varepsilon$ transport equation calculation

$\sigma_{\mathrm{k}} \quad$ constant for $k$ transport equation calculation

$\rho \quad$ fluid density

$\rho_{l} \quad$ liquid density

$\rho_{\text {lsat }} \quad$ liquid density at saturation

$\rho_{l}^{o} \quad$ liquid density at a given temperature condition

$\rho_{v s a t} \quad$ vapour density at saturation

$\rho_{v} \quad$ vapour density

$\Psi \quad$ fluid compressibility

$\Psi_{l} \quad$ liquid compressibility 
$\Psi_{v} \quad$ vapour compressibility

\section{INTRODUCTION}

Nowadays, the increasing concern for the environment protection has made the reduction of the pollutants and fuel consumption become one of the most important challenges in diesel engines field. Many of the improvements achieved to reduce the emissions of these engines are due thanks to the advances in fuel injection systems. In this sense, the design of the injection systems and the operating conditions are fundamental on the internal nozzle flow and spray development, and therefore in the airfuel mixing and combustion processes [1], [2], [3], [4], [5], [6], [7], [8].

In order to improve the atomization of the sprays and the mixing process, modern diesel engines work at high injection pressures. Nevertheless, the use of injection pressures up to $180 \mathrm{MPa}$ favours the appearance of the cavitation phenomenon in diesel injector nozzles. This phenomenon takes place when the fuel at high velocity flows through a contraction like a nozzle and the pressure falls below the saturation pressure. Then, the liquid starts to cavitate, and as a consequence a local change of state from liquid to vapour occurs.

Cavitation generates vapour bubbles within the flow, increasing the maximum velocity in the core of the discharge orifices. This velocity increases for two mainly reasons. On one hand, if there is vapour along the orifice wall, the liquid will have a slip boundary condition [3]. On the other hand, when the fluid is cavitating it cannot fill the entire channel, and so the effective channel diameter is reduced compared to the geometrical one [3], [9]. 
Despite the fact that cavitation could be not desirable in pumps or valves since it could cause important damages, in diesel injectors cavitation leads to an increase in the spray cone angle, which is expected to improve the air-fuel mixing process [10], [11], [12].

As shown by several studies, cavitation is strongly influenced by the internal nozzle characteristics [10], [13]. In this sense, it seems clear that the injection process may affect cavitation development [14], [15], [16] since the geometry upstream the orifices changes during the opening and closing of the injector as a consequence of the variable needle lift position.

Unfortunately, the extremely small geometry of the holes strongly difficults experimental studies of the internal nozzle flow. One alternative is the use of large scale models, although scale effects have been recognized to be very important [16]. For these reasons, the use of CFD tools has increased in the last years making it possible to obtain unlimited level of details about the behavior of the flow.

Cavitation modeling could be performed considering two different approaches: two fluid flow models [18] or continuum flow models [19], [20], [21], [22]. The first ones treat the liquid and vapour phases separately, whereas the continuum nozzle flow models (or homogeneous equilibrium models) consider the liquid and vapour as a homogeneous mixture. In these models, an equation of state which relates pressure and density (normally called barotropic equation) allows the calculation of the growth of cavitation.

As demonstrated by a lot of experimental works, turbulence plays a major role on the flow features [23], [24], [25]. Hence, CFD models must take into account the turbulence effects to accurately reproduce the behavior of the flow. The Direct Numerical Simulation (DNS) approach is the most accurate methodology for turbulent flow prediction, as it directly solves the governing equations on a very fine grid without 
modeling. However, the computational cost needed to perform a DNS makes it unfeasible to use this approach for engineering applications. The Large Eddy Simulation technique (LES) is an alternative to simulate turbulent flows [26], [27], [28] which only resolves those eddies that are larger than the grid size and models the rest of them (subgrid scale). This technique can be considered as a bridge between DNS and the cheapest method, Reynolds Averaged Navier-Stokes (RANS). The RANS approach solves the Reynolds-averaged Navier-Stokes equations with models for turbulent quantities, decomposing the fluid properties into averaged and fluctuating components. In the current work, a multiphase compressible code together with a Reynolds Averaged Navier-Stokes approach has been used to study the effects of the needle movement on the cavitation development and the flow features in a real multi-hole diesel nozzle. Since experimental tests at different fixed partial lifts are not possibly accomplished in the second generation solenoid Bosch injector used, the code has been validated in terms of mass flow, momentum flux and effective velocity only at fully needle lift conditions $(250 \mu \mathrm{m})$.

The simulations have been performed at different needle lifts, keeping the injection pressure constant at $160 \mathrm{MPa}$ and varying the backpressure from 3 to $50 \mathrm{MPa}$. They have allowed not only a complete analysis of the cavitation inception and development, but also an in-depth study of the mass flow choking induced by the cavitation phenomenon [29], [30], [31], [32], [33], momentum flux evolution and turbulence development for each needle position.

For these purposes, the present paper is organized in the following way. Firstly, a brief explanation of the equations used to model both cavitation and turbulence is made. Secondly, a definition of the nozzle geometry and the calculated simulations is done in section 3 . The validation of the code at fully needle lift conditions and the main results 
about the influence of the needle position obtained from the computational study have been included in sections 4 and 5, respectively. Finally, the most important conclusions from this study have been presented in section 6 .

\section{DESCRIPTION OF THE CFD APPROACH}

\subsection{Cavitation modeling}

As stated in the introduction, there are two main methods for modeling cavitation phenomena, being a homogeneous equilibrium model with a barotropic equation of state the most suitable method due to the high pressures and velocities that take place in diesel injector nozzles [21], [22], [33], [34].

The code used in the present work, implemented in OpenFOAM $₫$ [35], assumes that liquid and vapour are always perfectly mixed in each cell, and takes into account the compressibility of the liquid and vapour phases.

The barotropic equation of state used in this model relates pressure and density:

$$
\frac{D \rho}{D t}=\Psi \frac{D p}{D t}
$$

where $\Psi$ is the compressibility of the mixture, defined as the inverse of the squared speed of sound:

$$
\Psi=\frac{1}{a^{2}}
$$

The barotropic equation of state (equation (1)) should be consistent with the liquid and vapour equations of state both at the limits when there is pure liquid or vapour, and also at intermediate states when there is a mixture of them.

The amount of vapour in the fluid is calculated with the $\gamma$ parameter, which is defined in equation (3). As it can be seen, the $\gamma$ parameter is 0 if the flow is not cavitating (only liquid phase), whereas $\gamma=1$ for fully cavitating flows (only vapour phase). 
$\gamma=\frac{\rho-\rho_{\text {lsat }}}{\rho_{\text {vsat }}-\rho_{\text {lsat }}}$

where $\rho_{v s a t}=\Psi_{v} \cdot p_{\text {sat }}$

The density of the mixture is calculated taking into account the amount of vapour in the fluid $(\gamma)$ together with a correction term based on the pressure (mixture's equilibrium equation of state):

$\rho=\gamma \cdot \rho_{v}+(1-\gamma) \cdot \rho_{l}+\psi\left(p-p_{s a t}\right)=(1-\gamma) \cdot \rho_{l}^{0}+\left[\left(\gamma \cdot \psi_{v}+(1-\gamma) \cdot \psi_{l}\right)-\psi\right] \cdot p_{s a t}+\Psi \cdot p$

with $\quad \rho_{l}^{0}=\rho_{l, s a t}-\Psi_{l} \cdot p_{\text {sat }}$

With regard to the compressibility of the mixture, it is modeled by a simple linear model:

$\Psi=\gamma \cdot \Psi_{v}+(1-\gamma) \cdot \Psi_{l}$

with $\Psi_{l}$ and $\Psi_{v}$ equal to the compressibility of the liquid and vapour, respectively.

Despite the fact that there are models which describe the compressibility of the mixture in a more physical way (Wallis or Chung), a linear model was chosen based on the convergence of the results and their stability.

As in the case of the compressibility, it is possible to obtain the viscosity of the mixture with a linear model in a similar way:

$\mu=\gamma \cdot \mu_{v}+(1-\gamma) \cdot \mu_{l}$

The methodology followed by the solver starts solving the continuity equation for $\rho$ (equation (9)):

$\frac{\partial \rho}{\partial t}+\nabla \cdot(\rho \vec{u})=0$

The value of density obtained is used to determine preliminary values for $\gamma$ and $\Psi$ by means of equation (3) and equation (7), and also to solve the momentum equation 
(equation (10)), which is used to get the matrices used to calculate the pressure-free velocity, $u$ :

$\frac{\partial(\rho \vec{u})}{\partial t}+\nabla \cdot\left(\rho \frac{\vec{u} \vec{u}}{2}\right)=-\nabla p+\nabla \cdot(\mu \nabla \vec{u})$

Then, an iterative PISO algorithm is used to solve for $p$ and correct the velocity to achieve continuity. The equation solved for the PISO loop is the continuity equation transformed into a pressure equation by use of the equation of state (equation (5)):

$$
\frac{\partial(\psi p)}{\partial t}-\left(\rho_{l}^{0}+\left(\psi_{l}-\psi_{v}\right) p_{s a t}\right) \frac{\partial \gamma}{\partial t}-p_{s a t} \frac{\partial \psi}{\partial t}+\nabla \cdot(\rho \vec{u})=0
$$

Once continuity has been reached, the properties $\gamma, \rho$ and $\Psi$ are updated by means of equations (3), (5) and (7), respectively. These equations are taken into account to solve the momentum equation again and so on, repeating the algorithm until convergence.

A preliminary study in order to quantify the influence of the numerical schemes chosen for each term of the equations was done. Its objective was to analyze how the different numerical schemes affect the solution in terms of convergence, stability and accuracy of the simulation results. As an example, Figure 1 shows the huge differences found in the mass flow of a nozzle (different from the nozzle used in the present paper) changing only the numerical scheme of the gradient terms. As a conclusion of this study, a Gauss linear scheme was chosen.

\subsection{Turbulence modeling}

The introduction of the turbulence effects in the code (which was validated in [33], [34] but neglecting the turbulence effects) has been done by RANS methods through a RNG k- $\varepsilon$ model. This method solves the Reynolds-averaged Navier Stokes equations with models for turbulent quantities, decomposing the fluid properties into averaged and fluctuating components. The RNG k- $\varepsilon$ model is based on the Boussinesq hypothesis and 
models the Reynolds stresses using an eddy or turbulent viscosity defined in equation (14). Then, it solves a transport equation for $\mathrm{k}$ (equation (15)) and $\varepsilon$ (equation (16)):

$$
\begin{aligned}
& \mu_{T}=C_{\mu} \cdot \rho \frac{k^{2}}{\varepsilon} \\
& \frac{\partial}{\partial t}(\rho k)+\frac{\partial}{\partial x_{i}}\left(\rho k u_{i}\right)=\frac{\partial}{\partial x_{j}}\left[\left(\mu+\frac{\mu_{T}}{\sigma_{k}}\right) \frac{\partial k}{\partial x_{j}}\right]+P_{k}-\rho \varepsilon \\
& \frac{\partial}{\partial t}(\rho \varepsilon)+\frac{\partial}{\partial x_{i}}\left(\rho \varepsilon u_{i}\right)=\frac{\partial}{\partial x_{j}}\left[\left(\mu+\frac{\mu_{T}}{\sigma_{\varepsilon}}\right) \frac{\partial \varepsilon}{\partial x_{j}}\right]+C_{1 \varepsilon}^{*} \frac{\varepsilon}{k} P_{k}-C_{2 \varepsilon} \rho \frac{\varepsilon^{2}}{k}
\end{aligned}
$$

where $C_{\mu}=0.0845, C_{\varepsilon 1}=1.42, C_{\varepsilon 2}=1.68$ and $\sigma_{k}=\sigma_{\varepsilon}=0.72$.

\section{NUMERICAL SIMULATIONS DESCRIPTION}

\subsection{Nozzle geometry and calculation set-up}

A six-hole microsac nozzle, mounted in a second generation solenoid Bosch injector, was used for the experimental and computational study. The internal geometry of the nozzle has been extracted using the methodology described by Macián et al.[36]. This methodology is based on the use of special silicone moulds of the nozzle. With the help of a scanning electron microscope, pictures of the moulds are taken and the nozzle geometry can be analyzed using a CAD software.

Table 1 depicts the main values of the six orifices and the standard deviation for all the geometrical parameters obtained by means of this methodology. As it is known, the inlet curvature radius together with the $k$-factor (which evaluates the degree of conicity relating the inlet and outlet diameters as shown by equation (17)) are two of the most important parameters inducing nozzles to cavitate [3], [10], [13]. Indeed, attending to its $\mathrm{k}$-factor value $(k$-factor $=0)$ the nozzle studied is cylindrical and so, prone to cavitate [10]. 


$$
k-\text { factor }=\frac{D_{i}[\mu m]-D_{o}[\mu m]}{10 \mu m}
$$

Once the internal geometry of the nozzle is known, it is possible to model it for CFD calculations. Figure 2 shows the modeled geometry at full needle lift conditions (250 $\mu \mathrm{m})$, which will be used to make the comparison with the experimental data at stabilized flow conditions [37].

The geometries modeled, which represent only one of the six orifices of the nozzle to speed up the calculations (all the orifices are similar), correspond to the volume occupied by the fluid in the nozzle, including the needle and nozzle wall, the sac and the orifice.

To study the influence of the needle position on the internal flow and cavitation appearance in depth, ten additional geometries have also been modeled with different needle lifts: $10,20,30,40,50,75,100,150,200$ and $250 \mu \mathrm{m}$. These geometries have been discretized in hexahedral cells keeping a partly structured grid that follows the direction of the flow (improving the stability and convergence rate [13]) and a small unstructured zone just after the orifice inlet. A previous mesh sensitivity study at full needle lift made it possible to choose the most appropriate mesh fineness, showing that the cell size in the hole should vary from $9 \mu \mathrm{m}$ in the orifice core (D/18.9) to a minimum value of $1.15 \mu \mathrm{m}$ in the near-wall region. For the rest of the cells in the nozzle the cell size should be fixed to $22.5 \mu \mathrm{m}$. With this cell size, the final mesh has around 84000 cells. The geometries that belonged to other partial lifts were meshed with the same cell size at the orifice and varying the cell size of the sac and the zone between the needle wall and nozzle wall, so that the ratio cell size/needle lift remained constant.

The grid infrastructure of the Spanish National Grid Initiative (es-NGI) [38] was used to perform the computation of the simulations. This grid infrastructure is part of the European Grid Initiative [39] that provides a stable Grid infrastructure for e-Science at 
European level. The es-NGI is composed of 15 sites with more than 12,000 CPUs and $300 \mathrm{~TB}$ of storage space. The calculations for this problem used a total of $34,668 \mathrm{CPU}$ hours.

The grid application has used a multi-parametric approach launching a total of 210 independent simulations. The grid application consist in two parts: on one side, there is an application that is able to perform the simulation; on the other side the orchestrating application has been developed, being in charge of submitting all the simulations, monitoring their status, and recovering the result files from the grid storage to the local storage. Due to the long time needed to perform the simulations, this application used check-pointing techniques to make it possible to recover the computation in the last saved state in case of failure.

\subsection{Boundary conditions and fluid properties}

A suitable boundary conditions set-up is fundamental to ensure the convergence and the accuracy of the simulations. These boundary conditions have been implemented adjusting a fixed pressure inlet and a non slip condition for the velocity at the orifice walls. As far as the pressure outlet is concerned, a mean pressure condition has been used. This boundary condition keeps the mean desired value, allowing zones with very low pressures due to the presence of vapour bubbles into the flow. This boundary avoids the imposition of a rigorous pressure outlet condition that could affect the nature of the vapour structures developed.

The pressure conditions used in the experimental test have been simulated, but a wide range of points at cavitating and non cavitating conditions have also been analyzed. These values can be seen in Table 2 .

With regard to fluid properties introduced in the calculations, the density and viscosity values were taken from the diesel fuel used in the experimental test (Repsol CEC RF- 
06-99) at $23^{\circ} \mathrm{C}$. The liquid compressibility was calculated from speed of sound measurements in diesel fuel and the vapour properties have been obtained from a similar fuel from Kärrholm et al. in [21], [22].

\section{VALIDATION OF THE CODE AT FULLY NEEDLE LIFT CONDITIONS}

\subsection{Mass flow}

For validation purposes, several injection rate tests were carried out with an Injection Rate Discharge Curve Indicator commercial System, whose measuring principle is the Bosch method rate meter [40]. This device allows displaying and recording all the information related to the chronological sequence of an individual fuel injection.

The injection rate tests were performed with a very large energizing time for four different backpressures $(3,5,7$ and $9 \mathrm{MPa})$, keeping the injection pressure constant at $160 \mathrm{MPa}$.

The averaged values of the mass flow profiles during the time in which the needle is fully open are plotted in Figure 3 (represented with triangles) together with the numerical simulations results for the needle lift $250 \mu \mathrm{m}$ (represented with rhombus). These values have been represented as a function of the squared root of pressure drop, being the pressure drop the difference between the injection pressure and the back pressure. The fact that the mass flow is constant for all the pressure conditions indicates that the nozzle is cavitating [3], [10], [13], [33]. The errors between the experimental and numerical results displayed above each couple of symbols are always between 2 and 5\% approximately, which means a high degree of agreement with experimental data. 


\subsection{Momentum flux and effective velocity}

The same pressure conditions used in the mass flow experiments were tested to measure the spray momentum flux. The momentum test rig is based on a pressurized chamber with a calibrated piezo-electric sensor which measures the force of the spray injected, which is equivalent to the spray momentum flux. The position and the impact area of this sensor are chosen to ensure that the spray impact area is clearly smaller than the area of the sensor. Under this assumption, and due to the conservation of momentum in axial direction, the force measured by the sensor will be the same as the momentum flux at the hole outlet or at any other axial location, since the pressure inside the chamber is kept constant and surrounds the entire spray, and fuel deflected is perpendicular to the axis direction [3].

The results of the momentum flux tests represented with triangles against CFD results can be seen on the left of Figure 4. Unlike mass flow results, the momentum flux increases with the pressure drop difference, showing that cavitation phenomenon does not induce momentum flux collapse, as $R$. Payri et al. [3] state. As can be seen from Figure 4, the deviation between the experimental values and momentum flux results predicted by the code at full needle lift for all the validated pressure conditions is less than $2 \%$, showing the great ability of the code to reproduce the behavior of the flow.

Once mass flow and momentum flux results have been obtained, it is possible to calculate the effective velocity at the outlet section, by means of equation (19):

$$
u_{e f f}=\frac{\dot{M}_{f}}{m_{f}}
$$

The effective velocity values as a function of the squared root of pressure drop have been plotted on the right of Figure 4. Obviously, despite the fact that the mass flow is constant for all the pressure conditions, the effective velocity continues increasing with the pressure drop due to the behavior of the momentum flux. For all the points 
simulated, the code underestimates the effective velocity with a maximum deviation of 5\%. Taking into account the mass flow, momentum flux and effective velocity validation, the code allows to accurately reproduce the behavior of the internal flow in diesel injector nozzles at cavitating conditions, predicting the flow features with high level of confidence.

\section{INFLUENCE OF THE NEEDLE LIFT -COMPUTATIONAL STUDY-}

\subsection{High needle lift vs. low needle lift}

In order to perform a complete study about the influence of the needle lift on the internal flow and cavitation phenomenon, 10 different lift levels and 21 different backpressures for each of them have been simulated at a fixed injection pressure (160 $\mathrm{MPa})$.

In order to facilitate the interpretation of the huge amount of data obtained from the simulations, the presentation of the results has firstly been done comparing a typical case at high needle lift $(250 \mu \mathrm{m})$ against another one at low needle lift $(30 \mu \mathrm{m})$. Once the differences found between both cases are analyzed and explained, the analysis of the internal flow at other needle lifts will be addressed.

\subsubsection{Mass flow \& cavitation appearance}

Figure 5 shows the evolution of the mass flow for all the simulated pressure conditions, together with the vapour field for both needle lifts $(30 \mu \mathrm{m}$ and $250 \mu \mathrm{m})$ at $P_{\text {back }}=47.5$ $\mathrm{MPa}$ and $P_{b a c k}=7 \mathrm{MPa}$.

As can be seen, for the case of $250 \mu \mathrm{m}$, the mass flow increases with the square root of pressure drop until it reaches critical cavitation conditions at $P_{\text {back }}=350 \mathrm{MPa}(\sqrt{\Delta P}=$ 11.18 MPa), characterized by the beginning of the mass flow collapse [3], [10], [31], 
[32], [33], [37] . From this point, the mass flow is always choked, remaining constant in spite of the diminution of the backpressure up to $3 \mathrm{MPa}(\sqrt{\Delta P}=12.53 \mathrm{MPa})$.

From the maximum backpressure $\left(P_{\text {back }}=50 \mathrm{MPa}\right)$ to backpressures higher than that of the critical cavitation conditions, the nozzle does not cavitate and therefore there is not any vapour bubble in the hole. Nevertheless, just before critical cavitation conditions the nozzles starts cavitating at the inlet radius [29], [41] and vapor grows along the upper surface of the orifice from the inlet corner as the backpressure decreases (see the right upper vapour field shown in Figure 5).

As far as the low needle lift is concerned and as it can be seen in the figure, the mass flow rate remains collapsed for all the pressure conditions simulated, being a consequence of the presence of cavitation in the area upstream the inlet hole section, where the needle closes against the nozzle wall blocking the exit of fuel.

Therefore, the mass flow collapse at high needle lift positions occurs at the orifice inlet, whereas for low needle lifts the critical section is placed at the needle closing. However, attending to the vapour field showed on the right part of Figure 5 (corresponding to $P_{b a c k}=7 \mathrm{MPa}$ ) it is possible to observe more differences in the vapour phase distribution of the nozzle orifice between both lifts. For the needle lift of $250 \mu \mathrm{m}$, at cavitating conditions, the vapour flows and grows along the upper surface of the orifice unchanging its appearance once it reaches the hole exit, whereas for a low needle lift the vapour appears in the needle seat and also in the lower part of the orifice for the lowest backpressures $(10,9,7,5$ and $3 \mathrm{MPa})$. Similar vapour phase distributions have been observed by Som et al.[42].

Whether the nozzle cavitates along the upper or the lower part of the orifice depends on the path followed by the fluid through the nozzle. As an example of these differences 
Figure 6 depicts the streamlines followed by some fluid particles for $250 \mu \mathrm{m}$ and $30 \mu \mathrm{m}$, together with the vapour phase field.

As shown in Figure 6, the direction of the fluid in the nozzle is completely different depending on the needle position. For the highest lift, fuel flows taking up all the volume between the walls of the needle and the nozzle before entering the hole. Once the flow reaches the orifice, due to the strong change of direction and cross section, the boundary layer tends to separate from the upper wall of the orifice and a vena contracta is developed. Due to the acceleration of the fluid in the volume between the vena contracta and the upper wall of the hole, the pressure suffers a considerable drop, favouring the cavitation phenomenon.

Nevertheless, for the low lift the fluid tends to flow closer to the needle wall, being accelerated in the needle closing due to the contraction, arriving to the sac and going into the orifice through the bottom part of the hole. As a consequence, the boundary layer tends to separate again, but in this case from the lower wall of the orifice. This fact accelerates the fluid between the established vena contracta and the orifice wall and forces a strong pressure decrease (and therefore the phase change from liquid to vapour).

The evolution of the pressure in the nozzle for both needle lifts can be seen in Figure 7, which analyzes the path followed by the fluid before reaching the orifice. As can be seen, for the highest needle lift, the pressure keeps almost constant along the nozzle before entering the discharge orifice. Nevertheless, for a low needle lift, the pressure suffers a strong drop in the critical section, the needle closing (section 10 in the figure), where cavitation takes place. From this section, the fuel pressure rises until going into the orifice through its bottom part. 


\subsubsection{Momentum flux and effective velocity}

As it happened for the mass flow, the behaviour of the internal flow in terms of momentum flux presents huge differences according to the needle position (see Figure 8).

For a high needle lift $(250 \mu \mathrm{m})$, momentum flux increases with the pressure drop. However, unlike the mass flow results, momentum flux does not suffer any collapse with cavitation development, only decreasing its slope once the critical cavitation conditions are reached [3].

As stated before, the behaviour for a low needle lift $(30 \mu \mathrm{m})$ strongly differs from high needle lifts, since momentum flux keeps constant while vapour is only located in the area where the needle closes against the nozzle wall. Nevertheless, when backpressure decreases and vapour bubbles appear in the bottom part of the orifice $\left(P_{\text {back }}=10 \mathrm{MPa}\right)$, momentum flux starts rising as a consequence of the viscosity reduction in the zone occupied by the vapour phase (vapour viscosity is almost six hundred times lower than liquid vapour).

This viscosity reduction of the flow (which reduces also the friction losses in the channel) and the reduction of the effective diameter due to the presence of vapour bubbles also force the increase in velocity at the outlet section [3] seen in Figure 8. The same reason justifies the velocity rise seen at $250 \mu \mathrm{m}$ between $\sqrt{\Delta P}=11.18 \mathrm{MPa}$ and $\sqrt{\Delta P}=12.53 \mathrm{MPa}$.

Indeed, if the effective velocity is calculated by means of equation (19) and plotted as a function of pressure drop (right plot of Figure 8) it is quite easy to appreciate the velocity rise when there is vapour in the nozzle orifice. 


\subsubsection{Flow coefficients}

Flow coefficients behaviour can help to analyze the behaviour of the flow in terms of mass flow, effective velocity and effective section of injection.

The first dimensionless parameter is the discharge coefficient $C_{d}$, which is defined as the mass flow obtained by $\mathrm{CFD}$ with regard to the maximum theoretical mass flow (equation (20)):

$C_{d}=\frac{m_{f}}{A_{o} \cdot \rho_{l} \cdot u_{t h}}=\frac{m_{f}}{A_{o} \sqrt{2 \cdot \rho_{l} \cdot \Delta P}}$

The discharge coefficient plotted in Figure 9 shows lower values of $C_{d}$ for the low needle lift as a consequence of the losses located mainly near the needle closing (previously seen in Figure 7) and the differences in the way the flow goes into the orifice. Furthermore, attending to the high needle lift case $(250 \mu \mathrm{m})$ the discharge coefficient seems to keep constant while there are no vapour bubbles, changing its behavior as soon as cavitation phenomenon appears [3]. This change can be noticeable not only at high lift from critical cavitations conditions, but also at low needle lifts where due to the presence of vapour (in the needle closing and/or the orifice) the discharge coefficient decreases as the back pressure decreases for all the pressure conditions. This $C_{d}$ drop is justified by the mass flow collapse induced by cavitation phenomenon as seen in section 5.1.1.

The second non-dimensional flow parameter is the velocity coefficient, $C_{v}$, which relates the effective velocity extracted from numerical simulations to the maximum theoretical Bernoulli velocity. It is calculated using equation (21).

$$
C_{v}=\frac{u_{e f f}}{u_{t h}}=\frac{u_{e f f}}{\sqrt{2 \cdot \frac{\Delta P}{\rho_{l}}}}
$$


As expected regarding the momentum flux results, the velocity coefficient remains constant until critical cavitation conditions. According to experimental results obtained by other authors [3], [10] once vapour appears in the orifice the effective velocity and velocity coefficient experiment an important rise due to reduction of friction losses (as a consequence of the viscosity decrease) and effective diameter.

For a low needle lift, such as $30 \mu \mathrm{m}$, the velocity coefficient slightly decreases as the backpressure decreases despite the fact that there is always vapour upstream the orifice. However, for the lowest backpressures, when vapour is also located in the orifice, $C_{v}$ follows the same behavior of $250 \mu \mathrm{m}$ at cavitating conditions, so it can be stated that the only presence of vapour bubbles inside the nozzle orifice induces to a velocity coefficient rise.

The third flow coefficient, $C_{a}$, is used to evaluate the reduction of the effective area with regard to the geometric one due to the presence of vapour bubbles into the flow reaching the orifice outlet (equation (22)).

$$
C_{a}=\frac{A_{e f f}}{A_{o}}=\frac{D_{e f f}^{2}}{D_{o}^{2}}
$$

This parameter can also be extracted by combining equation (20) and equation (21):

$$
C_{a}=\frac{C_{d}}{C_{v}}
$$

This dimensionless coefficient has also been represented in Figure 9. Observing the plot, the area coefficient follows the expected behavior, since it remains constant with values near to 1 while there is no vapour in the nozzle orifice. When the discharge pressure is small enough to force the appearance of vapour bubbles in the orifice, the area coefficient decreases as a consequence of the arrival of bubbles to the exit section 
(and the consequent reduction of liquid phase effective area) [3] and/or the flow separation from the wall.

\subsection{Evolution of the internal flow characteristics with the needle lift}

Once the typical behaviour of the flow at high and low needle lift positions is understood, the analysis of the internal flow at other needle lifts is done in this section. The upper left plot of Figure 10 shows the evolution of the mass flow for all the pressure conditions and needle lifts simulated. As can be seen, from a needle lift of 10 $\mu \mathrm{m}$ to $75 \mu \mathrm{m}$, the mass flow increases from very small values $(\approx 1.2 \mathrm{~g} / \mathrm{s})$ to typical values of full needle lift conditions for this injector nozzle (48-52 g/s). Indeed, for needle lifts higher than $75 \mu \mathrm{m}$, the mass flow remains invariable for all the simulated backpressures, showing a similar behavior for the lifts of 75, 100, 150, 200 and $250 \mu \mathrm{m}$. For all the needle positions higher or equal than $75 \mu \mathrm{m}$, the flow behavior is similar to that one seen in the previous section at $250 \mu \mathrm{m}$; whereas for the cases between 10 and 50 the behavior is similar to the one obtained for $30 \mu \mathrm{m}$, where mass flow collapse is due to the presence of vapour bubbles in the needle closing.

As it happened with the mass flow results, the momentum flux remains insensitive once the needle arrives to $75 \mu \mathrm{m}$, varying from near zero values for the lowest needle position, and increasing its value when the needle goes up (see the right plot of Figure 10).

Obviously, as the effective velocity and non dimensional coefficients (depicted in Figure 10 and 11, respectively) are calculated from mass flow and momentum flux results, these parameters follow the same trends, with a continuous increase up to $75 \mu \mathrm{m}$ and keeping constant for any higher needle lift. 
Finally, another interesting aspect to remark is the differences in terms of the pressure conditions needed to force cavitation to appear in the orifice. As stated before, the pressure drop at needle closing increases as the needle descends. Hence, differences in the cavitation field are expected at different needle positions for the same pressure conditions. For that purpose, a continuous line has been drawn in the velocity plot included in Figure 10 indicating the point at which cavitation starts in the hole for needle lifts between $10 \mu \mathrm{m}$ and $50 \mu \mathrm{m}$. As can be seen, cavitation appears later as the needle lift decreases, due to the fact that the pressure just before the inlet is lower as the needle descends and therefore a lowest backpressure is needed to achieve the critical cavitation conditions in the orifice inlet.

\subsection{Turbulent kinetic energy}

From the point of view of turbulence development inside the nozzle, the turbulent kinetic energy, defined as the mean kinetic energy per unit mass associated to eddies in turbulent flows, is one of the most interesting parameters to analyze the flow. Its analysis becomes a very useful tool, especially taking into account the huge differences in the geometry derived from the different needle positions.

Turbulent kinetic energy contours in the middle plane of the whole nozzle have been plotted in Figure 12, for needle lifts of 20,50 and $250 \mu \mathrm{m}$ for $P_{i n j}=160 \mathrm{MPa}-P_{\text {back }}=7$ MPa. As can be seen, the location of the most turbulent zone in the nozzle varies depending on the needle position.

For high needle lifts, the upper part of the orifice is the most turbulent zone of the nozzle, whereas for low needle lifts the needle closing becomes the most critical zone in terms of turbulence intensity. These differences can be justified by taking into account the pressure drop seen in Figure 7, since for needle lifts $\leq 50 \mu \mathrm{m}$ the flow experiments a 
strong pressure fall in the needle closing, whereas for high needle lifts the flow suffers the highest pressure drop in the orifice inlet as a consequence of the direction change of the flow.

As explained, turbulence development in the nozzle is clearly related to pressure drop. Thus, not only a location change of the turbulent zone is expected with the needle position. Due to the higher pressure drop in the needle closing, the turbulence intensity increases as the needle goes down (Figure 7). Indeed, comparing the k contours for 20 and $50 \mu \mathrm{m}$, it is possible to observe an important increase of the maximum turbulence intensity represented in black colour. This result agrees with the behaviour observed experimentally by Arcoumanis et al. [43] in transparent nozzles for different needle lifts.

\section{CONCLUSIONS}

In the present paper a complete study about the influence of the needle position on the internal flow and cavitation phenomenon in diesel injector nozzles has been done modeling cavitation with a homogeneous equilibrium model. Its validation against experimental data at full needle lift conditions has demonstrated a great accuracy of the code in terms of mass flow, momentum flux and effective velocity at typical operating conditions of diesel engines. Once validated, an extended computational study of 210 simulations (combining one injection pressure, twenty-one backpressures and ten different needle lifts) has been performed, drawing the following main conclusions:

- For high needle lifts, the mass flow increases with the square root of pressure drop until critical cavitations conditions are reached, characterized by the beginning of the mass flow collapse. However, for low lifts, the mass 
flow is always choked as a consequence of the presence of vapour in the needle closing.

- At cavitating conditions, the vapour flows along the upper surface of the orifice at high needle lifts; whereas for low needle lifts the vapour bubbles appear in the needle closing without reaching the orifice, and also in the lower part of the orifice for the lowest backpressures.

- Unlike the mass flow results at high needle lifts, momentum flux does not suffer any collapse with cavitation development. For low needle lifts momentum flux keeps constant while vapour is only located in the area where the needle closes against the nozzle wall. If vapour bubbles appear also in the bottom part of the orifice, a momentum rise takes place due to the reduction of viscosity in the near-wall region where vapour appears.

- Due to the reduction of effective diameter and viscosity, the presence of vapour in the nozzle orifice forces an increase of velocity at the outlet section.

- The mass flow, momentum flux and effective velocity remain insensitive once the needle reaches $75 \mu \mathrm{m}$.

- The turbulence development depends on the needle lift and is strongly related to pressure evolution in the nozzle, being higher at low needle lifts.

\section{ACKNOWLEDGMENTS}

This work was partly sponsored by "Vicerrectorado de Investigación, Desarrollo e Innovación" of the "Universitat Politècnica de Valencia" in the frame of the project "Estudio de la influencia del uso de combustibles alternativos sobre el proceso de 
inyección mediante GRID computing (FUELGRID)" and by "Ministerio de Ciencia e Innovación" in the frame of the project "Estudio teórico-experimental sobre la influencia del tipo de combustible en los procesos de atomización y evaporación del chorro Diesel (PROFUEL)", reference TRA2011-26293. This support is gratefully acknowledged by the authors.

\section{REFERENCES}

[1] G.M. Faeth, L-P Hsiang and P-K Wu, Structure and Breakup Properties of Sprays, International Journal of Multiphase Flow, 1995, 21, 99-127.

[2] S.H. Park, H.K. Suh and C.S. Lee, Effect of bioethanol-biodiesel blending ratio on fuel spray behavior and atomization characteristics, Energy \& Fuels 2009, 23, pp. 4092-4098.

[3] R. Payri, J.M. García, F.J. Salvador, and J. Gimeno, Using spray momentum flux measurements to understand the influence of diesel nozzle geometry on spray characteristics, Fuel 2005, vol. 84, pp. 551-561.

[4] H.K. Suh and C.S. Lee, Effect of cavitation in nozzle orifice on the diesel fuel atomization characteristics, International journal of heat and fluid flow, 2008, 29, pp. 1001-1009.

[5] R. Payri, F.J. Salvador, J. Gimeno and J. De la Morena, Effects of nozzle geometry on direct injection diesel engine combustión process, Applied termal engineering, 2009, vol. 29, pp. 2051-2060.

[6] S.H. Park, S.H. Kim and C.S. Lee, Mixing stability and spray behavior characteristics of diesel-ethanol-methyl ester blended fuels in a common-rail diesel injection system, Energy \& Fuels, 2009; 23, pp. 5228-5235. 
[7] J.M. Desantes, R. Payri, F.J. Salvador and A. Gil. Development and validation of a theoretical model for diesel spray penetration, Fuel 2006, vol. 85, pp. 910917.

[8] J.M. Desantes, R. Payri, J.M. García, F.J. Salvador, A contribution to the understanding of isothermal diesel spray dynamics, Fuel 2007, vol. 86, pp. 1093-1101.

[9] D.P. Schmidt and M.L. Corradini, The internal Flow of Diesel Fuel Injector Nozzles: a Review, International Journal of Engine Research 2001, vol. 2, n⿳⺈⿴囗十

[10] F. Payri, V. Bermúdez, R. Payri, F.J. Salvador, The influence of cavitation on the internal flow and the spray characteristics in diesel injection nozzles, Fuel 2004, vol. 83, pp. 419-431.

[11] R. Payri, F.J. Salvador, J. Gimeno and J. de la Morena, Study of cavitation phenomena based on a technique for visualizing bubbles in a liquid pressurized chamber, Internal Journal of Heat and Fluid Flow 2009, vol. 30, pp. 768-777.

[12] J.M. Desantes, F.J. Salvador, J.J. López and J. De la Morena, Study of mass and momentum transfer in diesel sprays based on X-ray mass distribution measurements and on a theoretical derivation, Experiments in Fluids, vol. 50, issue 2, pp. 233-246.

[13] V. Macián, R. Payri, X. Margot and F.J. Salvador, A CFD Analysis of the Influence of Diesel Nozzle Geometry on the inception of Cavitation, Atomization and Sprays 2003, 13, 579-604.

[14] R. Payri, F.J. Salvador, P. Martí-Aldaraví and J. Martínez-López, Using onedimensional modeling to analyse the influence of the use of biodiesels on the dynamic behavior of solenoid-operated injectors in common rail systems: 
Detailed injection system model, Energy Conversion and Management 2012, vol. 54, pp. 90-99.

[15] F.J. Salvador, J. Gimeno, J. De la Morena and M. Carreres, Using onedimensional modeling to analyse the influence of the use of biodiesels on the dynamic behavior of solenoid-operated injectors in common rail systems: Results of the simulations and discussion, Energy Conversion and Management 2012, vol. 54, pp. 122-132.

[16] J.W. Lee, K.D. Min, K.Y. Kang, C.S. Bae, E. Giannadakis, M. Gavaises and C. Arcoumanis, Effect of piezo-driven and solenoid-driven needle opening of common rail diesel injectors on internal nozzle flow and spray development, Proceedings of the Institution of Mechanical Engineers, DOI: 10.1243/14680874JER00806.

[17] C. Mishra and Y. Peles, Size scale effects on cavitating flows through microorifices entrenched in rectangular microchannels, Journal of microelectromechanical systems 2005, vol. 14, nº 5, pp. 987-999.

[18] E. Giannadakis, M. Gavaises, H. Roth and C. Arcoumanis, Cavitating Modelling in Single-Hole Diesel Injector Based on Eulerian-Lagrangian Approach, THIESEL 2004, Conference on Thermo and Fluid Dynamic Processes in Diesel Engines, Valencia, Spain, September, 10-13, 2004.

[19] T.G. Liu , B.C. Khoo and W.F. Xie, Isentropic one-fluid modelling of unsteady cavitating flow, Journal of computational physics, vol 201, 1, 80-108, 2004

[20] C. Habchi, N. Dumont, O. Simonin, Multidimensional simulation of cavitating flows in diesel injectors by a homogeneous mixture modeling approach, Atomization and sprays, vol. 18, pp. 129 - 162, 2008. 
[21] F. Peng Kärrholm, Numerical Modelling of Diesel Spray Injection, Turbulence Interaction and Combustion, PhD. Thesis, Chalmers University of Technology, 2008.

[22] F. Peng Kärrholm, H. Weller and N. Nordin, Modelling injector flow including cavitation effects for Diesel Applications, Proceedings of FEDSM2007, 5th Joint ASME/JSME Fluids Engineering Conference, July 30August 2, San Diego, California, USA.

[23] A. Sou, S. Hosokawa and A. Tomiyama, Effects of cavitation in a nozzle on liquid jet atomization, International Journal of Heat and Mass Transfer, vol. 50, pp. 3575-3582, 2007.

[24] A.K. Singhal, M.M. Athavale, H. Li and Y. Jiangs, Mathematical basis and the full cavitation model, J. Fluids Eng., vol. 124, pp. 617-624, 2002.

[25] J. W. Lindau, R. F. Kunz, D.A. Boger, D. R. Stinebring and H.J. Gibeling, High Reynolds number unsteady multiphase CFD modeling of cavitating flows, J. Fluids Eng., vol. 124, pp. 607-616, 2002.

[26] U. Piomelly, Large-eddy simulation: achievements and challenges, Progress in Aerospace Sciences, 1999, 335-362.

[27] G.R. Tabor, M.H. Baba-Ahmadi, Inlet conditions for large eddy simulation: A review, Computer and Fluids 39, 2010, 553-567.

[28] R. Payri, B. Tormos, J. Gimeno and G. Bracho, The potential of Large Eddy Simulation (LES) code for the modeling of flow in diesel injectors, Mathematical and Computer modeling 52, 2010, 1151-1160.

[29] C. Mishra and Y. Peles, Cavitation in flow through a micro-orifice inside a silicon microchannel, Physics of fluids vol. 17, No 1, 013601. 
[30] R. Payri, F.J. Salvador, J. Gimeno and L.D. Zapata, Diesel nozzle geometry influence on spray liquid-phase fuel penetration in evaporative conditions, Fuel 2008, vol. 87, pp. 1165-1176.

[31] C. Soteriou, R. Andrews, M. Smith, Further studies of cavitation and atomization in Diesel injection, SAE Paper 1999-01-1486, 1999.

[32] W.H. Nurick, Orifice cavitation and its effect on Spray Mixing, Journal of Fluids Engineering 1976, vol. 98.

[33] F.J. Salvador, S. Hoyas, R. Novella, J. Martínez-López, Numerical simulation and extended validation of two-phase compressible flow in Diesel injector nozzle, Proceedings of the Institution of Mechanical Engineers, Part D, Journal of Automobile Engineering, vol. 225, pp. 545-563, 2011.

[34] F.J. Salvador, J.-V. Romero, M.-D. Roselló, J. Martínez-López, Validation of a code to model cavitation phenomena in Diesel injector nozzles, Mathematical and Computer Modelling 52 (2010), 1123-1132.

[35] OpenFOAM ${ }^{\circledR}$ is a registered trade mark of OpenCFD Limited http://www.opencfd.co.uk/openfoam/index.html

[36] V. Macián, V. Bermúdez, R. Payri and J. Gimeno, New technique for the determination of the internal geometry of diesel nozzle with the use of the silicone methodology, Experimental techniques, vol. 27 (2), pp. 39-43, 2003.

[37] R. Payri, H. Climent, F.J. Salvador and A.G. Favennec, Diesel injection system modeling. Methodology and application for a first-generation common rail system, Proc. Inst. Mech. Engrs. vol.218, part D, 2004.

[38] Spanish National Grid Initiative http://www.es-ngi.es/

[39] European Grid Initiative http://www.egi.eu 
[40] R. Payri, F.J. Salvador, J. Gimeno and G. Bracho, A new methodology for correcting the signal cumulative phenomenon on injection rate measurements, Experimental techniques, vol. 32, pp. 46-49, 2008.

[41] J.M. Desantes, R. Payri, F.J. Salvador and J. De la Morena, Influence of cavitation phenomenon on primary break-up and spray behavior at stationary conditions, Fuel 89 (2010), 3033-3041.

[42] S. Som, S.K. Aggarwal, E.M. El-Hannouny and D.E. Longman. Investigation of nozzle flow and cavitation characteristics in a diesel injector, Journal of Engineering for Gas and Turbines and Power, April 2010, vol. 132, 042802-1.

[43] C. Arcoumanis, H. Flora, M. Gavaises, N. Kampanis and R. Horrocks, Investigation of cavitation in a vertical multi-hole diesel injector. SAE Paper 1999-01-0524, 1999. 


\section{LIST OF TABLE AND FIGURE CAPTIONS}

Table 1: Nozzle's geometrical characteristics.

Table 2: Pressure conditions simulated.

Figure 1. Mass flow as a function of time for different gradient schemes.

Figure 2. Nozzle simulated (at maximum needle lift).

Figure 3. Comparison of experimental and numerical results in terms of mass flow at full needle lift conditions.

Figure 4. Comparison of experimental and numerical results in terms of momentum flux and effective velocity at full needle lift conditions.

Figure 5. Mass flow and vapour phase averaged field for 30 and $250 \mu \mathrm{m} . P_{i n j}=160$ $\mathrm{MPa}-P_{b a c k}=50-3 \mathrm{MPa}$.

Figure 6. Streamlines and vapour phase for the needle lifts of 250 and $30 \mu \mathrm{m} . P_{i n j}=160$ $\mathrm{MPa}-P_{b a c k}=7 \mathrm{MPa}$.

Figure 7. Evolution of the pressure between the pressure inlet boundary condition and the sac for 30 and $250 \mu \mathrm{m} . P_{i n j}=160 \mathrm{MPa}-P_{b a c k}=7 \mathrm{MPa}$.

Figure 8. Momentum flux and effective velocity for 30 and $250 \mu \mathrm{m} . P_{i n j}=160 \mathrm{MPa}-$ $P_{\text {back }}=50-3 \mathrm{MPa}$.

Figure 9. Dimensionless flow coefficients for $30 \mu \mathrm{m}$ and $250 \mu \mathrm{m} . P_{i n j}=160 \mathrm{MPa}-P_{b a c k}$ $=50-3 \mathrm{MPa}$.

Figure 10. Mass flow, momentum flux and effective velocity for all the needle lifts simulated.

Figure 11. Dimensionless flow coefficients for all the needle lifts simulated.

Figure 12. Turbulent kinetic energy contours at needle lifts of 20, 50 and $250 \mu \mathrm{m}$ for $P_{i n j}$ $=160 \mathrm{MPa}-P_{b a c k}=7 \mathrm{MPa}$. 


\begin{tabular}{|c|c|c|c|c|c|c|}
\hline Orifices & $D i[\mu \mathrm{m}]$ & $D o[\mu \mathrm{m}]$ & $\boldsymbol{k}$-factor [-] & $\boldsymbol{r}[\boldsymbol{\mu \mathrm { m } ]}$ & $\boldsymbol{r} / \mathrm{Do}[-]$ & $\boldsymbol{L} / \mathrm{Do}[-]$ \\
\hline 6-hole & $170 \pm 1$ & $170 \pm 1$ & $0 \pm 1.4$ & $13 \pm 1$ & $0.074 \pm 0.01$ & $5.71 \pm 0.04$ \\
\hline
\end{tabular}

Table 1: Nozzle's geometrical characteristics.

\begin{tabular}{|c|c|}
\hline $\begin{array}{c}\text { Injection pressure } \\
(\mathrm{MPa})\end{array}$ & Backpressure $(\mathrm{MPa})$ \\
\hline & $3-5-7-9-10-12.5-15-17.5-20-$ \\
160 & $22.5-25-27.5-30-32.5-35-37.5-$ \\
& $40-42.5-45-47.5-50$ \\
\hline
\end{tabular}

Table 2: Pressure conditions simulated. 

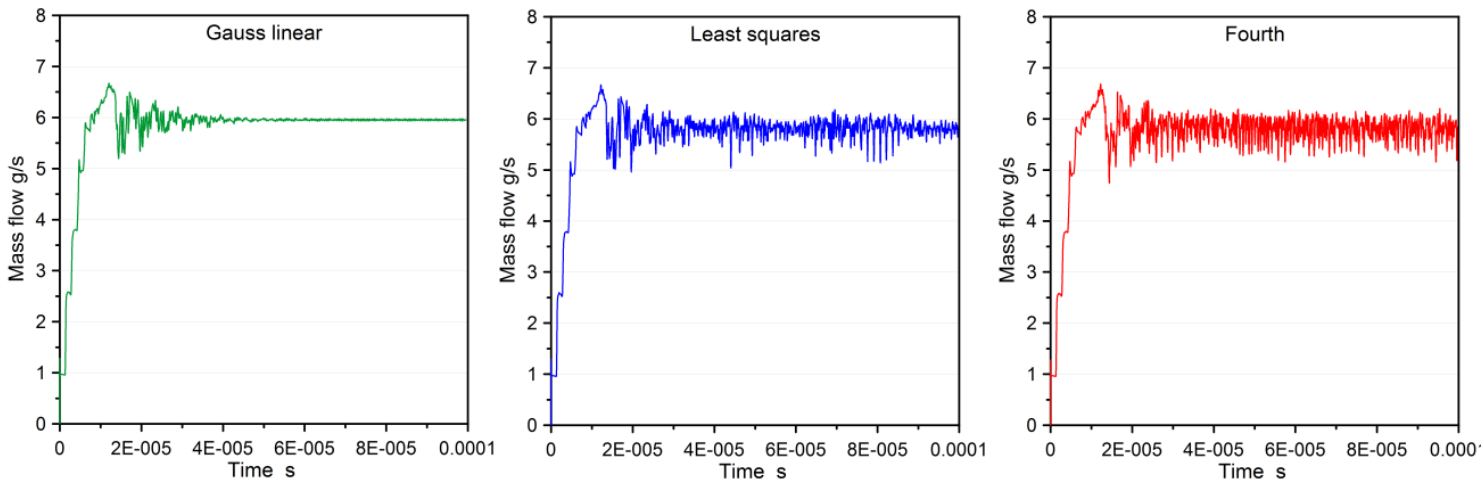

Figure 1. Mass flow as a function of time for different gradient schemes. 


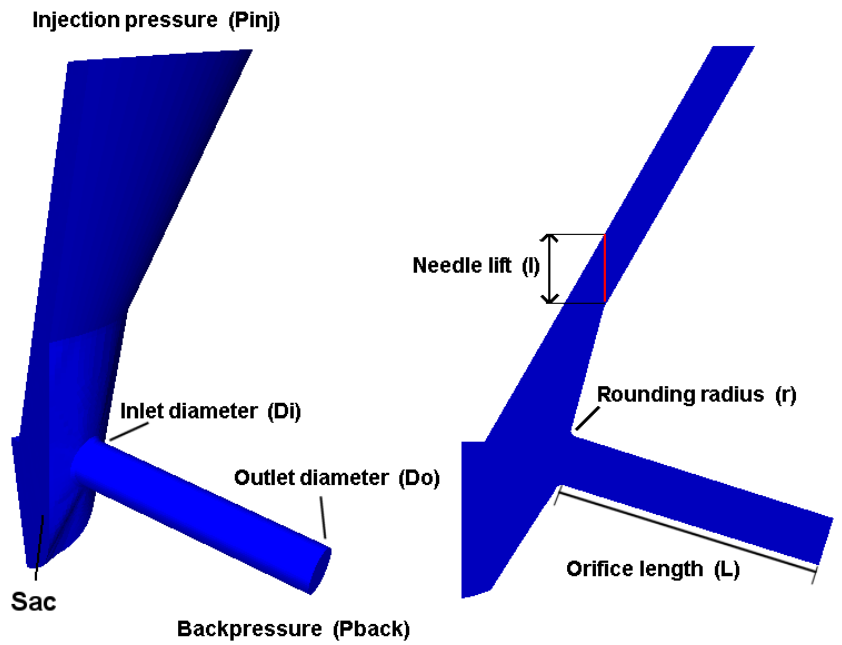

Figure 2. Nozzle simulated (at maximum needle lift). 


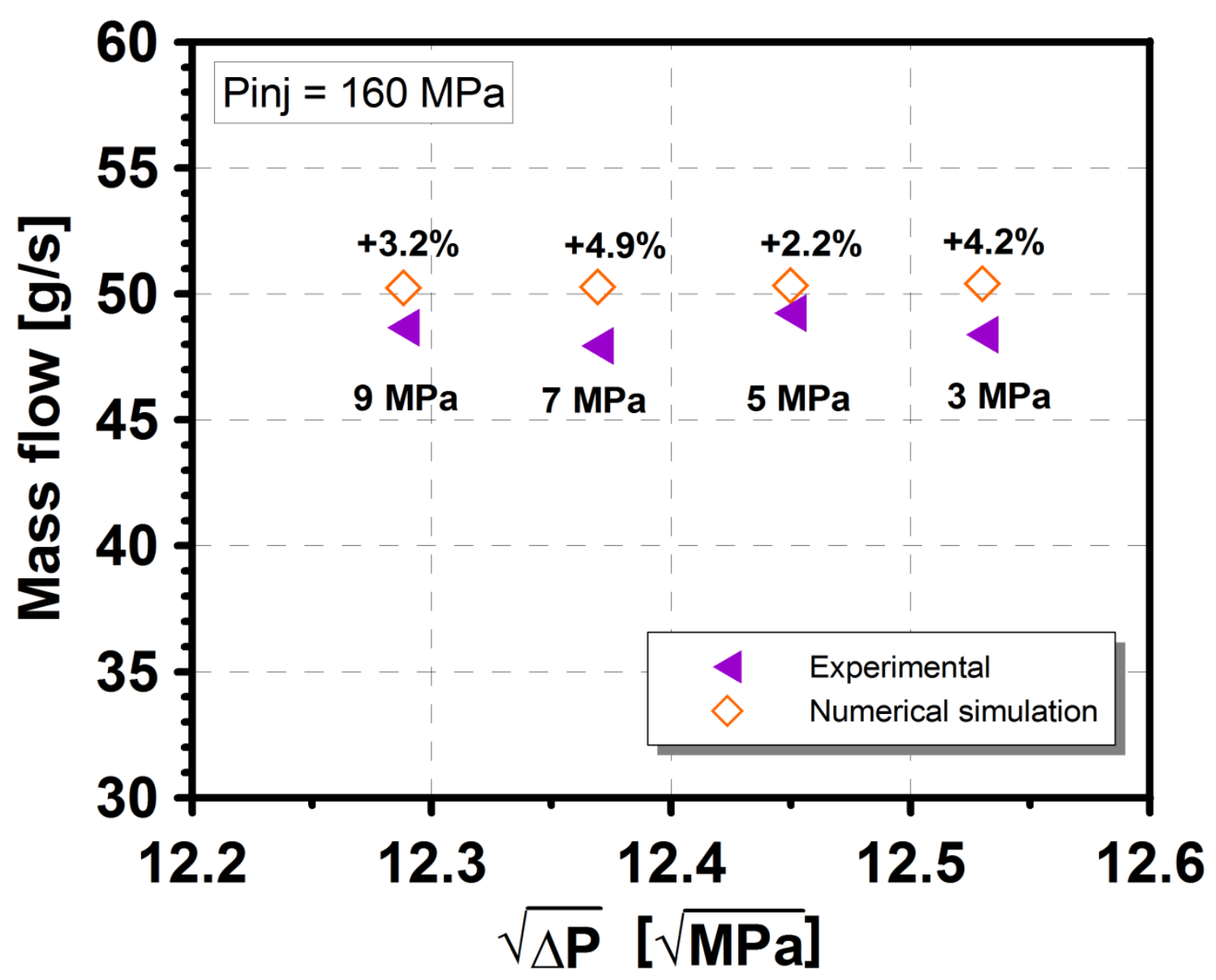

Figure 3. Comparison of experimental and numerical results in terms of mass flow at full needle lift conditions. 

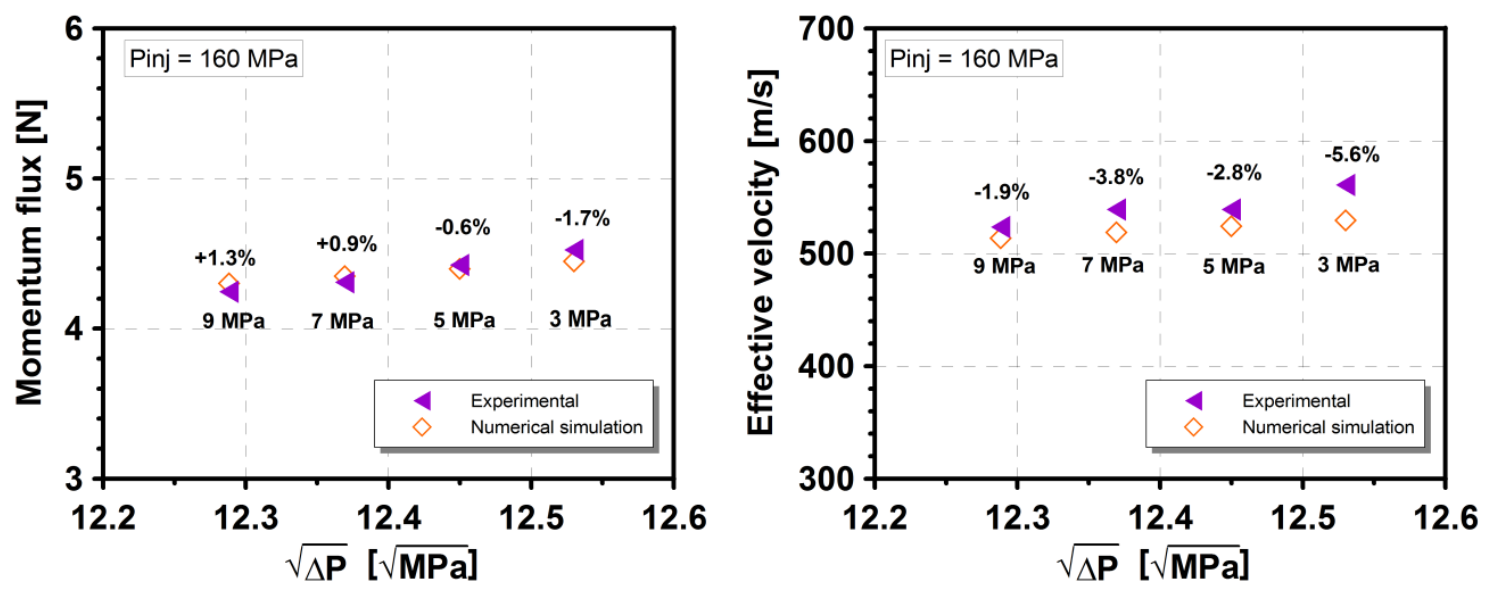

Figure 4. Comparison of experimental and numerical results in terms of momentum flux and effective velocity at full needle lift conditions. 


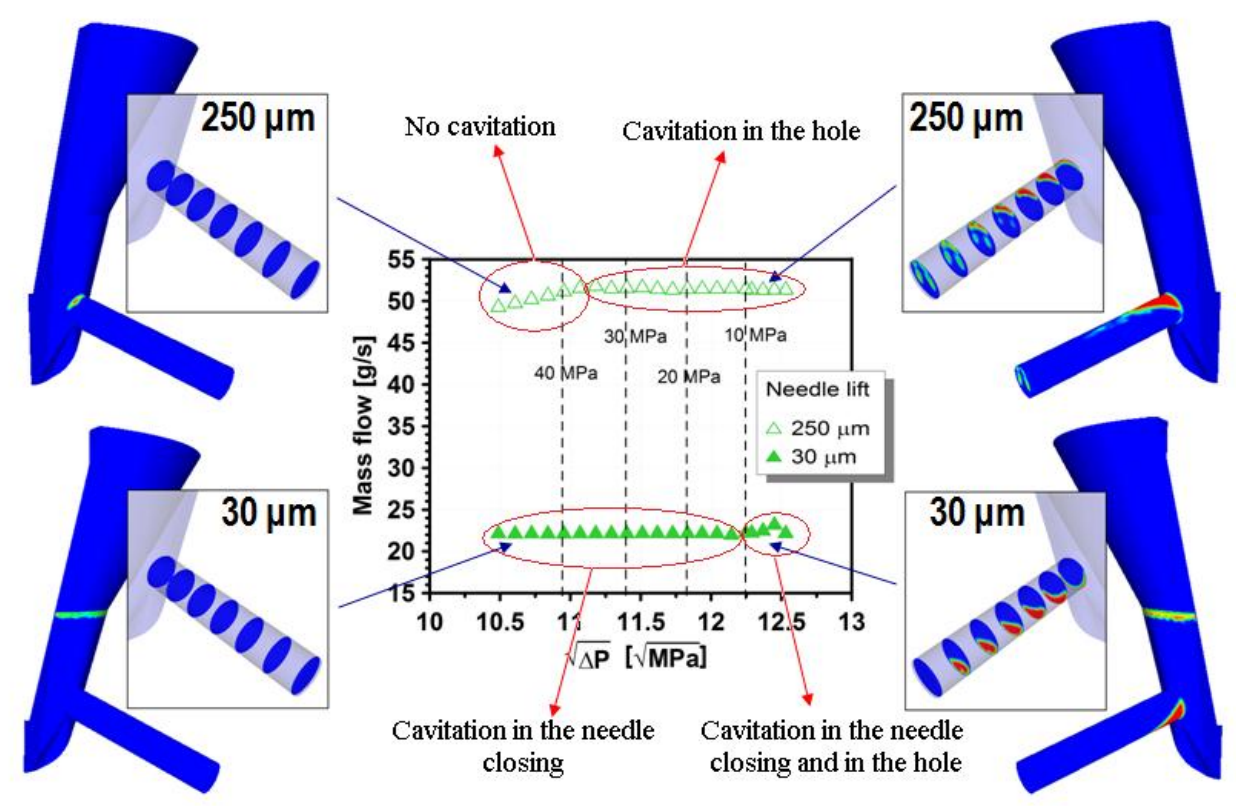

Figure 5. Mass flow and vapour phase averaged field for 30 and $250 \mu \mathrm{m} . P_{i n j}=160$ $\mathrm{MPa}-P_{b a c k}=50-3 \mathrm{MPa}$. 


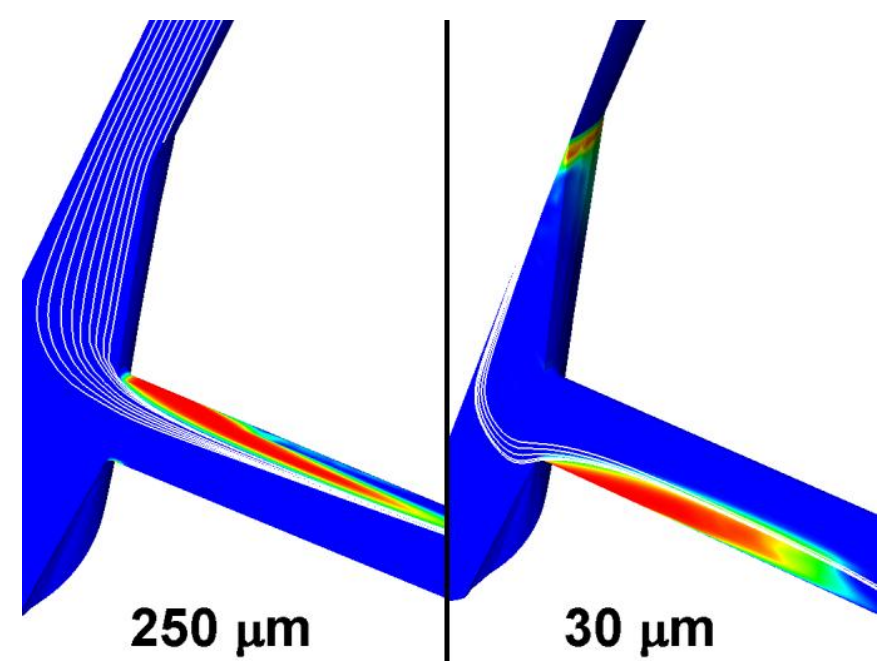

Figure 6. Streamlines and vapour phase for the needle lifts of 250 and $30 \mu \mathrm{m} . P_{i n j}=160$ $\mathrm{MPa}-P_{b a c k}=7 \mathrm{MPa}$. 


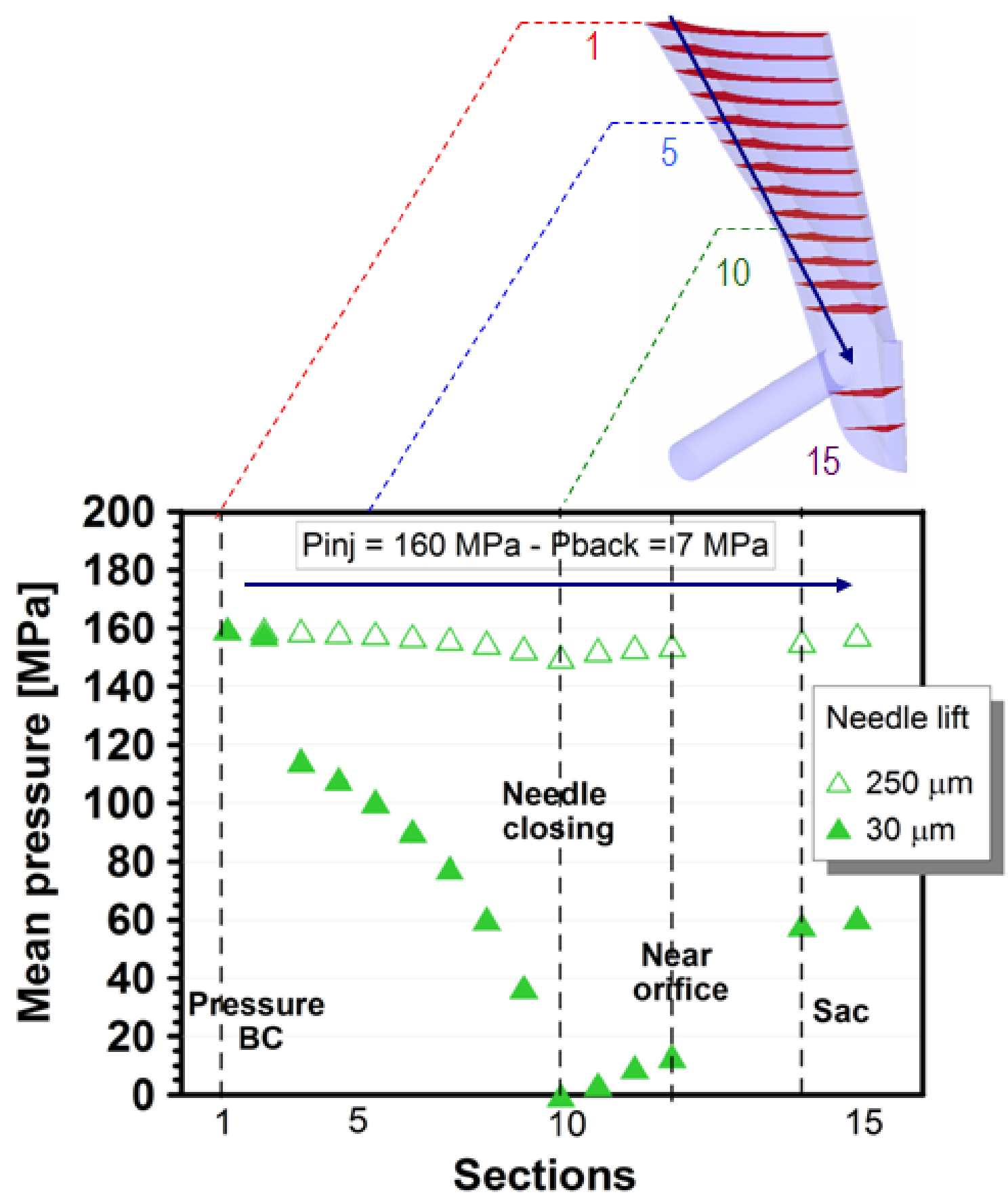

Figure 7. Evolution of the pressure between the pressure inlet boundary condition and the sac for 30 and $250 \mu \mathrm{m} . P_{i n j}=160 \mathrm{MPa}-P_{b a c k}=7 \mathrm{MPa}$. 

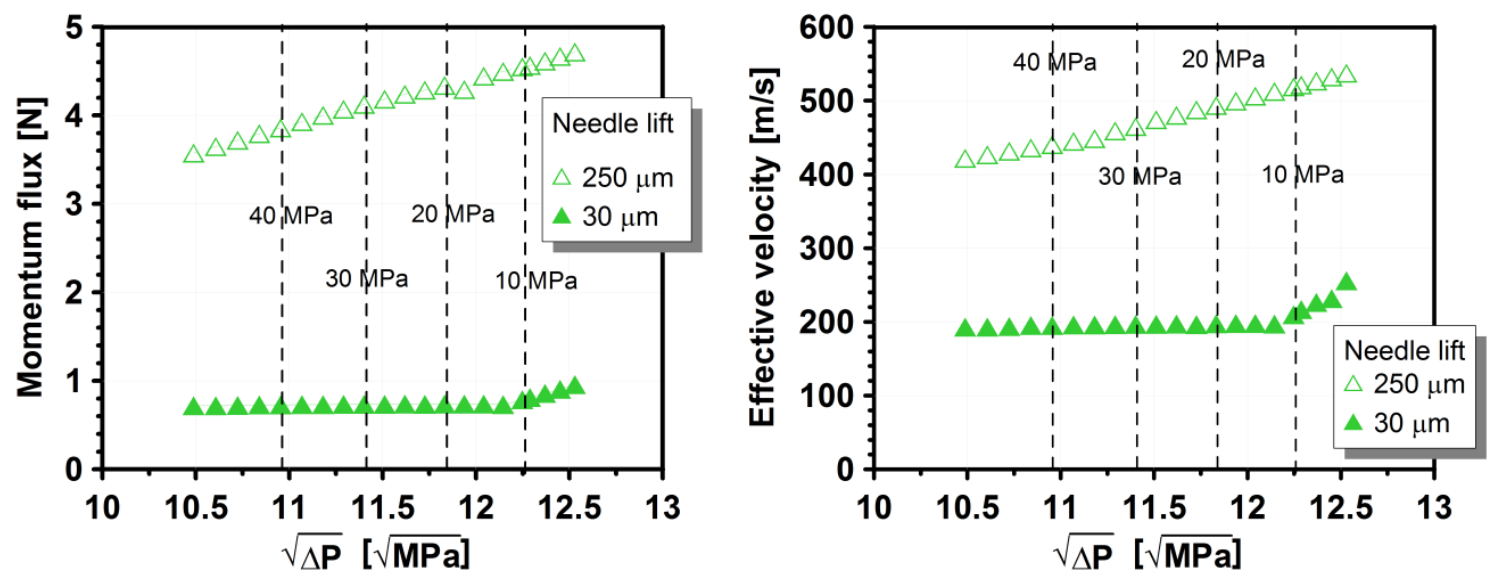

Figure 8. Momentum flux and effective velocity for 30 and $250 \mu \mathrm{m} . P_{i n j}=160 \mathrm{MPa}-$ $P_{\text {back }}=50-3 \mathrm{MPa}$. 


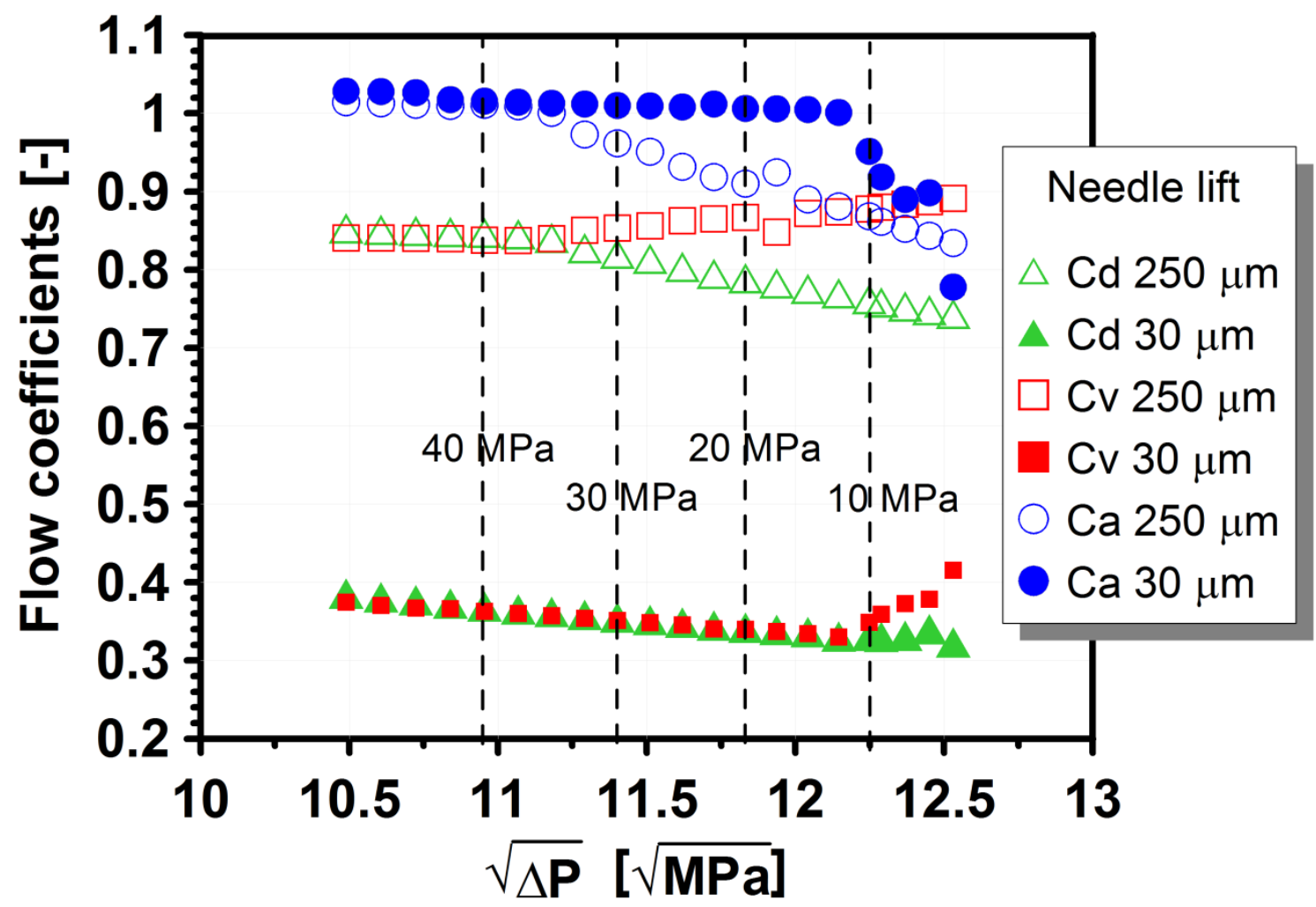

Figure 9. Dimensionless flow coefficients for $30 \mu \mathrm{m}$ and $250 \mu \mathrm{m} . P_{i n j}=160 \mathrm{MPa}-P_{b a c k}$ $=50-3 \mathrm{MPa}$. 

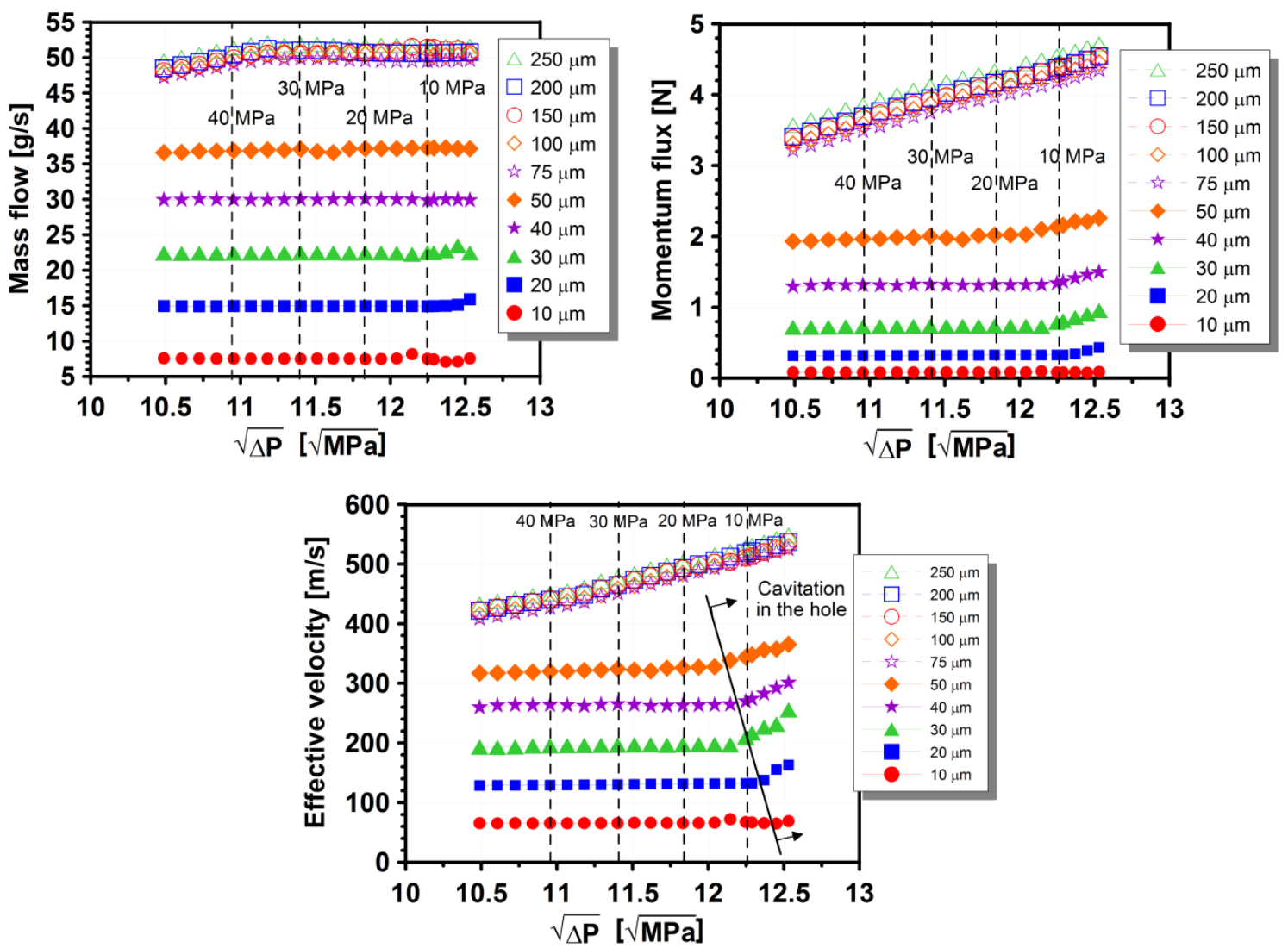

Figure 10. Mass flow, momentum flux and effective velocity for all the needle lifts simulated. 

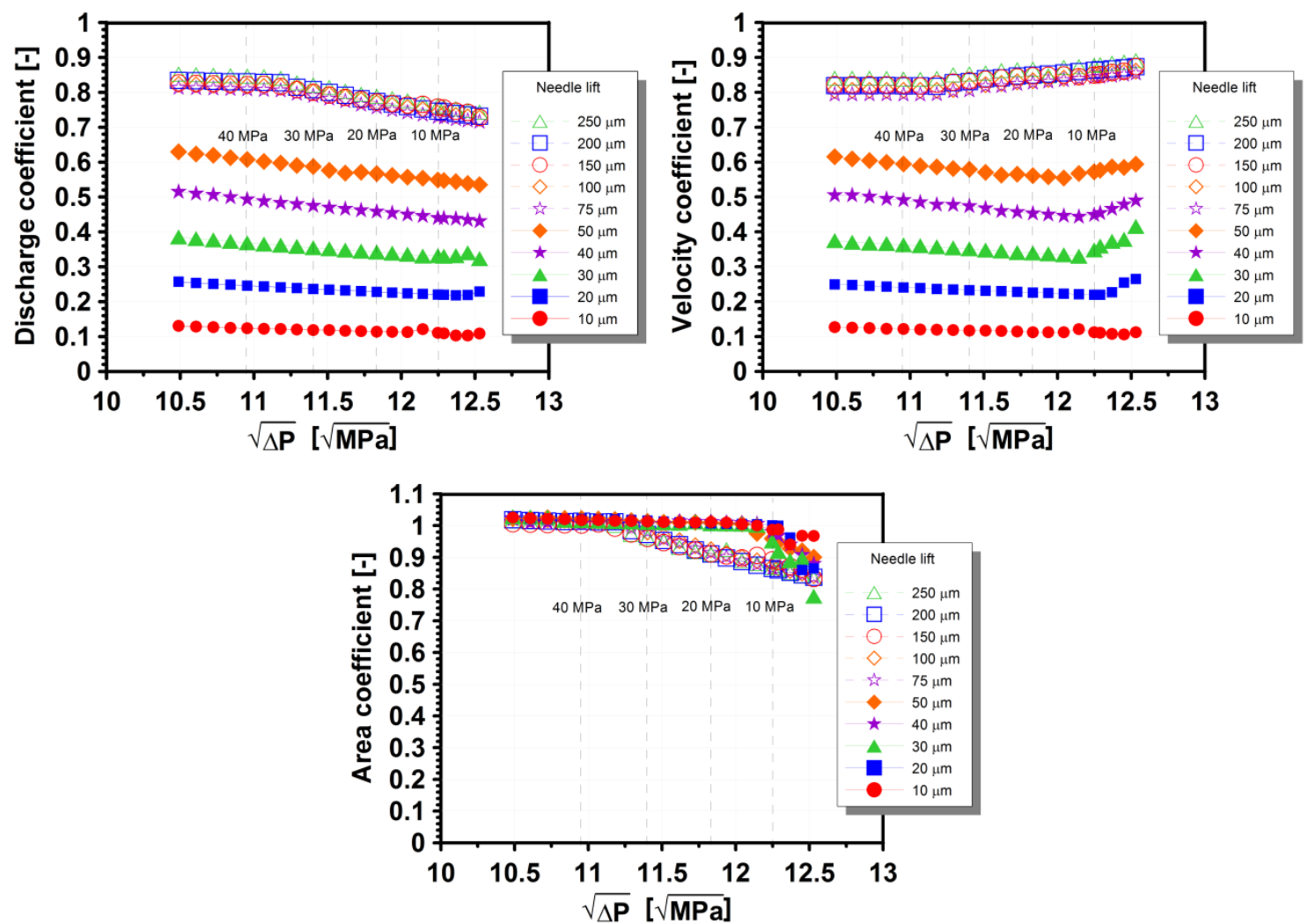

Figure 11. Dimensionless flow coefficients for all the needle lifts simulated. 


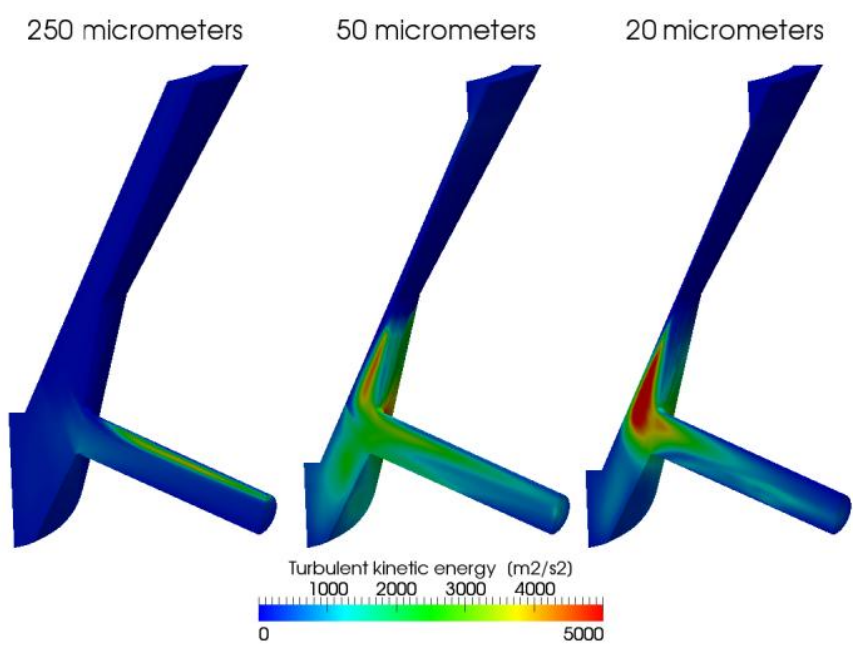

Figure 12. Turbulent kinetic energy contours at needle lifts of 20, 50 and $250 \mu \mathrm{m}$ for $P_{i n j}$ $=160 \mathrm{MPa}-P_{\text {back }}=7 \mathrm{MPa}$. 